\title{
Research on Management of Scientific Funds in Universities Jie $\mathrm{Li}^{1}$, a , Chang $\mathrm{Liu}^{1}$ and Bo $\mathrm{Lu}^{1}$ \\ ${ }^{1}$ Department of Science and Technology, Dalian University, Dalian, China, 116622 a27673959@qq.com
}

Keywords: Universities; Fund management; Surplus funds

\begin{abstract}
Recently, a series of rules and regulations have been put forward to strengthen the management of scientific research funds in colleges and universities, which arouse strong reactions among the researchers of colleges and universities. The problems which exist in the management of scientific research funds in colleges and universities are analyzed in this article. Besides, the necessity of strengthening the management in the new period is emphasized. At last, it puts forward some reasonable suggestions in the aspects of improving the system environment of management of scientific research funds, regulating the balance of funds management, enhancing the transparency of expenditure of scientific research funds and the using efficiency.
\end{abstract}

\section{Introduction}

To strengthen the management of surplus funds is an important part of the government to strengthen the management of scientific research. In recent years, with the deepening of the national anti-corruption and the deepening of the audit, the university has been exposed to the phenomenon of illegal use of scientific research funds, which causes widespread concern. People generally fall into two different views. On one hand, public media continue to over-exaggerate the abuse of research funds, although there were some cases like that. In reality it is taking, misappropriation of funds case. On the other hand, the researchers is widely considered to current scientific research funds management and reimbursement system is not reasonable, management is too strict and meticulous, complex process, waste much of their time and energy in addition to the scientific research. The number and quality of scientific research projects have declined.

However, science research is different from the ordinary development of infrastructure and project construction. It is also different from the management of administrative office funds. The management of scientific research funds has its own objective laws. Not only should it respect the characteristics of scientific research activities, but also protect and stimulate the creativity of scientific researchers. These arguments ask us to introspect the problems existing in the management system of scientific research funds.

\section{Innovation Theory to Improve the Mechanism of Scientific Research Management}

The Necessity to Improve Scientific Research Management. The research fund is a necessary prerequisite to guarantee that the scientific research carry out smoothly. The government research fund is always the most stable and fundamental source for most colleges and universities. It is an essential support for humanity social sciences research and basic subject science research. In recent years, our country's total amount of investment in science and technology has been increasing, and the input intensity occupies the leading position in the new developing countries (refer with: Table 1). There is a serious contradiction between the increasing scientific research investment and the backward research funds management system, which has seriously restricted the improvement of the innovation ability of scientific research in our country.

The Problems Existing in Management of Scientific Research Funds. Take surplus scientific research funds management as an example, except for National Science and Technology Support Plan Funds Management Measures which clearly stipulates: after project acceptance inspection 
passing, relevant departments should close the account in time within one month. Given that funds would not be used up, surplus fund should be refunded to the original departments which granted funds.

Table 1 List of China's Science and Technology Funds from 2010 to 2014

\begin{tabular}{lllllll}
\hline Year & $\begin{array}{l}\text { The national } \\
\text { research and } \\
\text { development } \\
\text { fund(billion) }\end{array}$ & $\begin{array}{l}\text { Growth } \\
\text { rate }\end{array}$ & $\begin{array}{l}\text { National fiscal } \\
\text { expenditure on } \\
\text { science and } \\
\text { technology (billion) }\end{array}$ & $\begin{array}{l}\text { Growth } \\
\text { rate }\end{array}$ & $\begin{array}{l}\text { University } \\
\text { science and } \\
\text { technology fund } \\
\text { (billion) }\end{array}$ & Growth rate \\
\hline 2014 & 1301.56 & $9.9 \%$ & 645.45 & $4.4 \%$ & 89.81 & $4.8 \%$ \\
2013 & 1184.66 & $15 \%$ & 618.49 & $10.4 \%$ & 85.67 & $9.8 \%$ \\
2012 & 1029.84 & $18.5 \%$ & 560.01 & $16.7 \%$ & 78.06 & $13.3 \%$ \\
2011 & 868.7 & $23 \%$ & 490.26 & $19.2 \%$ & 68.89 & $15.3 \%$ \\
2010 & 706.26 & $21.7 \%$ & 411.44 & $27.6 \%$ & 59.73 & $27.6 \%$ \\
\hline
\end{tabular}

Data sources: national science and technology funds into statistical bulletin

There are no definite management regulations on surplus funds for some other Projects, such as projects supported by National Social Science Foundation Ministry of education of humanities and social science project, Education department projects supported by Provinces and cities, social science planning projects, Social Science Association projects. National natural fund newly issued the funds management regulation on the national natural science projects which stipulates: project surplus funds would be arranged by supporting organization within 2 years, given that surplus funds would not be used up, they should be refunded to National Natural Science Foundation (NSFC) [2].

\section{Countermeasures to Improve Scientific Research Funds Management}

To Improve the System Construction and Environment Construction. To build a good system environment of scientific research funds, we must both respect the objective laws of scientific research and grasp the art of management firstly. For example, a prevailing payment term at present is one-time allocation, especially on or below the provincial level projects. National Social Science Fund allocated $90 \%$ for the first time, and the project implementation period is generally two to three years, some basic research projects period is five years. So in order to improve the efficiency of funds, we may consider that we can choose batch allocation.

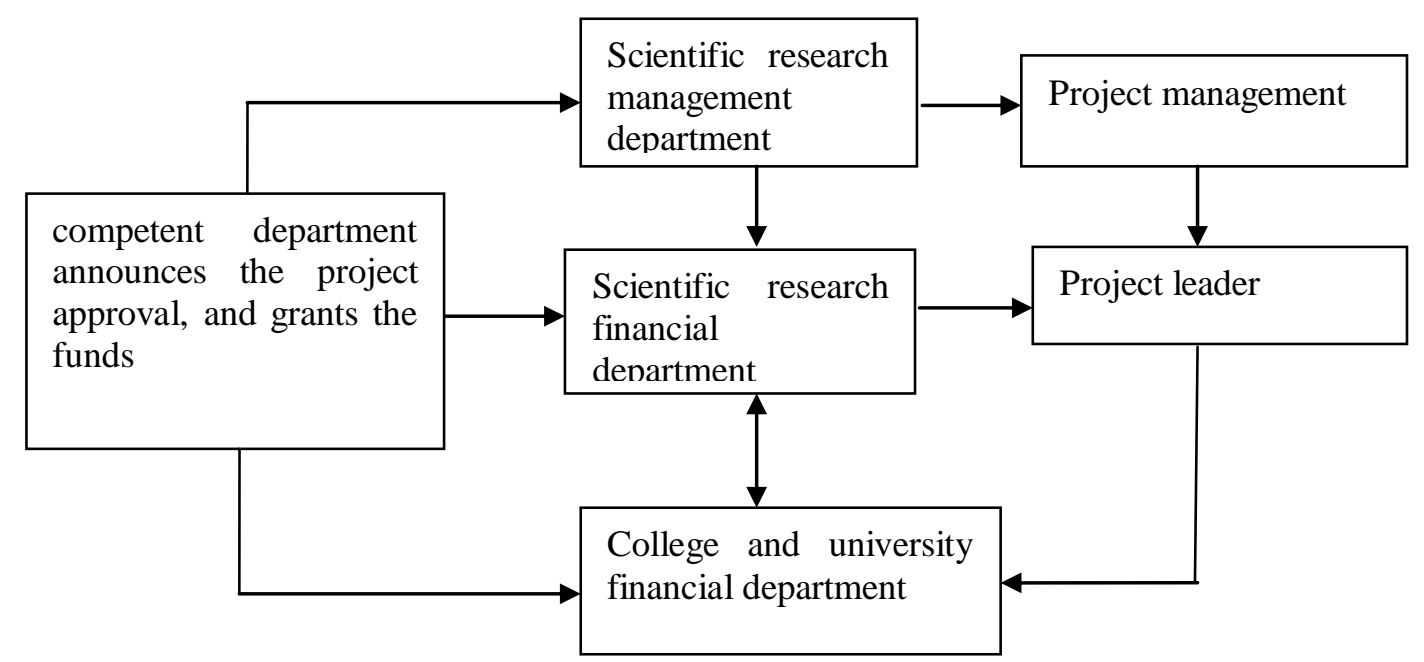

Figure 1. The form of organization management of scientific research funds

The first batch is allocated for $50 \%$ of the amount, after the medium-term inspection, $40 \%$ of the amount would be granted, after the project is done completely, the remaining $10 \%$ would be granted. This method will not only monitor how well the project goes, but also ensure the safety of research 
funds, what's more, it can meet the actual needs of the project funds. Secondly, colleges and universities that have sufficient conditions should establish scientific research funds management institutions, responsible for assisting and guiding the researchers to make reasonable budget, provide total access services from notice of funds launch, budget implementation progress report, suggestions on using the funds, adjustment of the budget and final accounts. Make policy consultation and tax relief together with other related departments [3] (refer with: Fig.1). Thirdly, set effective laws and regulations to make it mandatory and serious to be executed. This can not only curb corruption from the source, but also protect the rights and interests of researchers.

To Standardize Surplus Funds Management, Improve Funds Efficiency. Surplus funds refer to the remaining funds after all scientific research tasks have been completed. The exploration nature of scientific research makes the budget uncertain. There are four main reasons for the surplus funds. First, the project proceeds more smoothly than expected. Second, is the person in charge of the project to declare the project for the budget period is too long or lack the necessary knowledge of budget preparation the budget and actual cost of a certain deviation in the rest of the money; the third is the project director save money. Forth, allocation of funds falls behind and so on [4].

The author thinks the regulation that the funds must be used up within the limited time, otherwise the funds will be all taken back is neither reasonable nor beneficial to the efficiency of using funds. It tends to result in shock tactics on money, being forced to spend money, waste of resources, loses of academic ethics and other problems. Surplus funds should be linked to the project and the credit evaluation. For the project which is completed on schedule and of good quality, the funds can be used on their own. But for the project seriously overdue completion or project was withdrawn a serious credit problems, surplus funds should be recovered and the project responsible for a unit of people and the research integrity records.

To Strengthen and Improve the Civil Service Card in the Use of All Kinds of Scientific Research, Enhance the Transparency in Research Spending. Civil Service Card has been put into use from the beginning of 2007 in some pilots, and acquires preferably effect. The application scope is mainly for the official administrative expenses. However, there is no large-scale use for the management of scientific research funds. Civil Service Card is a kind of credit card, the time and amount of every revenue and expenditure has detailed records, the record information can be supervised the financial departments, which turn the supervision of results into process of supervision. In addition to that, using Civil Service Card can also reduce the cost and risk in using cash. Since using scientific research funds is complex, Civil Service Card applied in research funding should also be further improved in the relevant system: first, strengthen cooperation, and constantly improve the using condition of the card. At present, credit card in the developed cities of China have been used widely, but in the backward area, payment terminals are still insufficient, even in some big cities, credit card cannot be accepted in train ticket agencies.

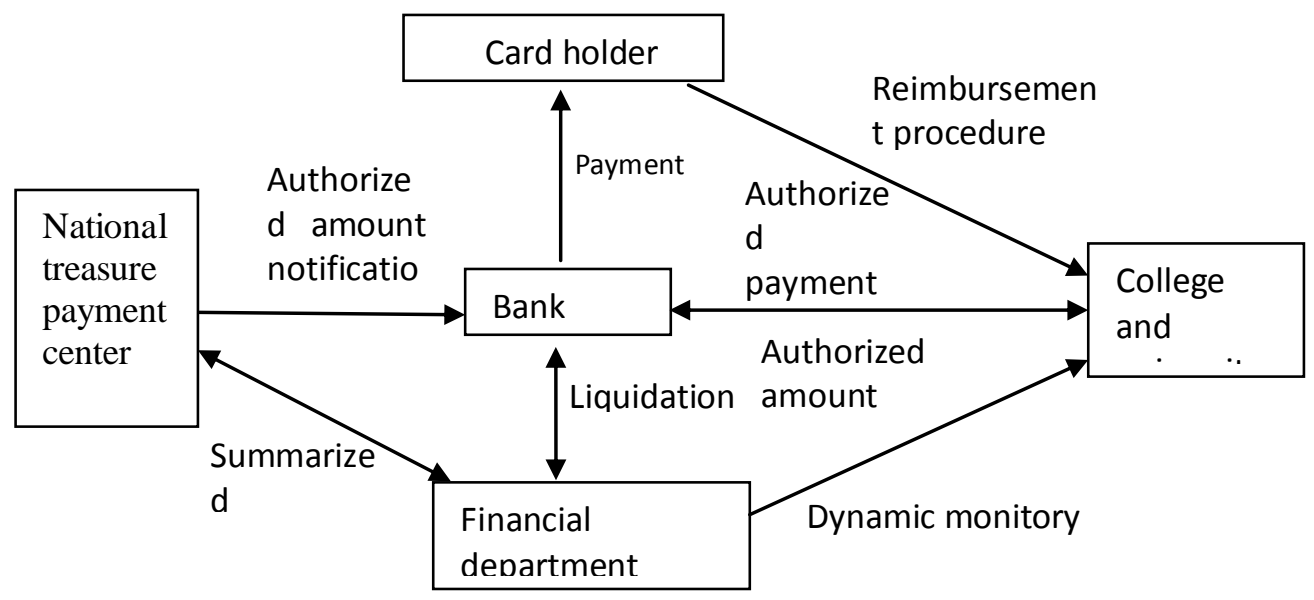

Figure 2. Civil service card repayment processes 
Therefore, promotion of civil service cards is not only related to the financial, banking, electronic payment systems, but also to government, businesses, customers and other aspects. Second, simplify the using procedures of civil service cards, and improve the cards using mechanism (refer with: Fig.2). Currently, the cards using process is: after expenditure, the users took invoices and record notes to finance department to claim the payment. When invoices were verified, the data information would be delivered to the bank, finally, the cards were refunded. During these processes, the problems such as staff limited, over workload would defer refund claim, which results in unnecessary overdue fine. New changes of claim refund habits would reduce the civil service cards efficiency. Therefore, researchers should be provided convenient and quick funding reimbursement mechanism, and make the main focus on scientific research. Third, relevant civil service cards Use details and supporting measures should conform to the scientific research work. Scientific research has its particularity and uncertainty. For instance, students would be involved in scientific research, and it is necessary to confirm that how students could apply or cancel of credit card. In addition, some subjects are required to carry out field investigation and to buy special test material, on that condition, credit cards cannot be used. University Finance department should consider these specific problems and support reimbursement.

The management of scientific research funds in colleges and universities is a scientific policy problem that spans macroscopy and microscopy, political and scientific. Scientific researchers should not only do a good job in scientific research, but also should establish legal conciousness and sense of responsibility. The government should create a good system environment for scientific research activities, respect the objective laws, be people oriented, and improve their management level, so as to ensure that the country's huge investment in scientific research is highly rational and efficient.

\section{Acknowledgements}

This work was supported by the Liaoning educational scientific research management think tank project (ZK2015071; ZK2015090); Liaoning Educational Science Planning (JGZXQDA021; JG15DB041); Liaoning Social Science Planning Fund Plan (L14CJY041); 2014 Liaoning BaiQianWan Talents Program (2014Q013); Liaoning Provincial Education Department (WJQ2015004); Dalian Jinzhou Science and technology project (RXYJ-RXSK-2015-002).

\section{References}

[1] M. Mao: Economist, (2016) No.3, p.151.

[2] Information on http://www.nsfc.gov.cn/publish/portal0/tab220/info48335.htm.

[3] Information on http://www.moe.edu.cn/publicfiles/business/htmlfiles/moe/index.html.

[4] H.T. Li and L. Xu.: Friends of the accounting, (2013) No. 4, p.109. 